\title{
Skin Involvement of Mantle Cell Lymphoma May Mimic Primary Cutaneous Diffuse Large B-cell Lymphoma, Leg Type
}

\author{
Ulrike Wehkamp, MD, ${ }^{*}$ Christiane Pott, MD, $\dagger$ Michael Unterhalt, MD, + Karoline Koch, MD, $\S$ \\ Michael Weichenthal, MD,* Wolfram Klapper, MD, $\S$ and Ilske Oschlies, MD§
}

\begin{abstract}
Mantle cell lymphoma (MCL) is a B-cell neoplasm with a variable and generally aggressive clinical course. So far our knowledge of skin involvement of MCL is limited. To understand the clinical and histopathologic features of MCL with skin involvement, the files of the Lymph Node Registry Kiel were screened for MCL diagnosed in the skin. Over a period of 13 years, 1321 biopsy specimens were diagnosed as MCL; among them, 14 patients $(1 \%)$ showed skin involvement. Of these, skin was the initial site of manifestation in $6 / 11(55 \%)$ cases. One patient presented with a skin-limited lymphoma. Furthermore, 7/12 $(58 \%)$ patients presented with lesions on the leg. The lymphomas were highly proliferative with blastoid cytology in 12/14 (86\%) cases. Moreover, the immunophenotype with expression of BCL2 (100\%), MUM-1/IRF4 (83\%), and IgM (82\%) and lack of CD10 $(25 \%)$ and BCL6 $(0 \%)$ closely resembled the features of primary cutaneous diffuse large B-cell lymphoma, leg type. Solely the expression of cyclin D1 (100\%) and the presence of $\mathrm{t}(11 ; 14)(100 \%)$ allowed a distinction from cases of primary cutaneous diffuse large B-cell lymphoma, leg type. Only 2 MCL cases with skin involvement presented with classical cytology. Interestingly, in these 2 cases skin involvement occurred simultaneously in a lesion of coexisting primary cutaneous marginal zone lymphoma. Our data suggest that clinical presentation on the leg and blastoid cytology along with high proliferation and expression of Bcl2, Mum-1/ IRF4, and IgM are typical for MCL involving the skin. Lymphomas with these features might be erroneously diagnosed as diffuse large B-cell lymphoma, leg type, if cyclin D1 staining is not performed.
\end{abstract}

From the *Department of Dermatology; $†$ Medical Department II; §Department of Pathology, Hematopathology Section, ChristianAlbrechts-University Kiel, Kiel; and †Department of Internal Medicine III, University Hospital of Munich, Munich, Germany.

Conflicts of Interest and Source of Funding: The authors have disclosed that they have no significant relationships with, or financial interest in, any commercial companies pertaining to this article.

Correspondence: Ulrike Wehkamp, MD, Schittenhelmstr. 7, 24105 Kiel, Germany (e-mail: uwehkamp@dermatology.uni-kiel.de).

Supplemental Digital Content is available for this article. Direct URL citations appear in the printed text and are provided in the HTML and PDF versions of this article on the journal's Website, www.ajsp.com.

Copyright (C) 2015 Wolters Kluwer Health, Inc. All rights reserved.
Key Words: mantle cell lymphoma, cyclin D1, primary cutaneous diffuse large B-cell lymphoma, Sox11, composite lymphoma

(Am J Surg Pathol 2015;39:1093-1101)

C lassical mantle cell lymphoma (MCL) is a mature Bcell neoplasm, which is characterized in the majority of cases by monomorphic small to medium-sized centrocytelike cells (classical cytology), a typical immunophenotype with expression of CD5 and cyclin D1, and the hallmark translocation $\mathrm{t}(11 ; 14)(\mathrm{q} 13 ; \mathrm{q} 32)$ as the underlying cause of constitutive cyclin D1 expression. In addition to classical MCL, rarer cytomorphologic variants of MCL have been described. The pleomorphic and blastic variants are usually associated with a higher proliferation rate and an aggressive clinical course. ${ }^{1}$ These large cell variants (pleomorphic and blastic, lumped under the term blastoid) account for about $8 \%$ to $9 \%$ of all MCLs. ${ }^{2}$ The disease is rare, accounting for approximately $8 \%$ of non-Hodgkin lymphomas, and manifests in elderly adults with a median age of 60 and a male predominance. ${ }^{1}$ This lymphoma has an aggressive clinical course with a median overall survival of 4 to 5 years. With few exceptions like the so-called "in situ" lymphomas, MCL is regarded as a genuine systemic lymphoma presenting in most cases with stage III or stage IV disease and leukemic dissemination. 3,4 Typical clinical sites of involvement are lymph nodes, spleen, gastrointestinal tract, and bone marrow. Nevertheless, infiltration of almost all organs has been described in the literature. ${ }^{1}$ However, skin infiltration of MCL seems to be a rare finding. To the best of our knowledge, published series of MCL infiltrating the skin include no more than 5 cases. ${ }^{5,6}$

In the current study, we evaluated the clinical and histopathologic features of MCL involving the skin, with a special focus on the differential diagnosis versus primary cutaneous diffuse large B-cell lymphoma, leg type (pcDLBCL-lt).

\section{MATERIALS AND METHODS}

\section{Patients and Specimens}

All cases of MCL diagnosed between 2001 and 2014 were identified in the files of the Lymph Node Registry in 
the Department of Pathology, University of Kiel. Among 1321 patients with the diagnosis MCL, 14 patients were diagnosed with MCL with skin infiltration. All cases were rereviewed by 2 expert hematopathologists (I.O. and W.K.) to confirm the diagnosis with respect to the currently accepted histopathologic and/or molecular criteria of the World Health Organization classification. ${ }^{1}$ Diagnostic slides and formalin-fixed and paraffin-embedded (FFPE) tissue specimens were used for further immunohistochemical analysis. Clinical information including age, sites of involvement, and stage at first diagnosis, primary treatment, and follow-up was provided by the treating oncologists. Three patients were treated within the framework of the European MCL Network, which provided clinical data. The study was performed in accordance with the guidelines of the institutional review board.

\section{Immunohistochemistry}

The analyses were performed on FFPE skin biopsy specimens. All cases were investigated for expression of CD20, CD10, Bcl6, Bcl2, CD23, CD5, IgM, Mum-1/IRF4, p53, Sox11, light chains, Ki67, and cyclin D1 using standard protocols (Supplementary Table 1, Supplemental Digital Content 1, http://links.lww.com/PAS/A286). Expression levels were scored by visual inspection as no expression ( $<25 \%$ positive lymphoma cells), weak expression $(26 \%$ to $50 \%$ ), medium expression (51\% to $75 \%$ ), and strong expression (> 75\%). To evaluate the Ki67 proliferation index, 200 lymphoma cells were counted according to the guidelines of the European MCL Network. ${ }^{7}$

\section{Fluorescence In Situ Hybridization}

Fluorescence in situ hybridization analysis was performed on paraffin slides with available material and analyzed for breaks in cyclin D1 using a break-apart probe and/or the presence of $\mathrm{t}(11 ; 14)(\mathrm{q} 13 ; \mathrm{q} 32)$ by a dualcolor fusion probe (all Vysis/Abbott, Green Oak, IL).

\section{RESULTS}

\section{Clinical Features}

Of 1321 biopsy specimens identified as MCL in the examined period of time, 14 were diagnosed in the skin $(1 \%)$. Table 1 summarizes the clinical features of these patients. Because of the retrospective nature of the study, the clinical information was incomplete and not available for all patients. Median age at first diagnosis was 72 years (50 to $85 \mathrm{y}$ ). Thirteen of 14 patients were male. In $6 / 12$ $(50 \%)$ patients the skin was the primary clinical site of involvement by MCL. Nevertheless, on staging, 5 of the 6 $(83 \%)$ patients with primary skin involvement were shown to suffer from systemic MCL with additional extracutaneous manifestation. In 1 patient the disease seemed to be limited to the skin. However, the follow-up of this patient is only 6 months so far. In 6/12 (50\%) patients skin manifestation occurred at relapse but was not present at primary diagnosis. In 2 patients lack of clinical information prevented a correlation of the analyzed specimen with the stage of the disease.

Four patients presented with unifocal and 10 with multifocal skin involvement. Lesions on the leg occurred in $7 / 12(58 \%)$ patients and were the site of the diagnostic biopsy for pathologic assessment. Interestingly, in 3

TABLE 1. Overview of Clinical Data of Patient Collective

\begin{tabular}{|c|c|c|c|c|c|c|c|c|c|c|c|}
\hline No. & Sex & $\begin{array}{l}\text { Age at } \\
\text { ID }\end{array}$ & $\begin{array}{l}\text { Stage } \\
\text { at ID }\end{array}$ & $\begin{array}{c}\text { Isolated/ } \\
\text { Multiple } \\
\text { Skin Lesions }\end{array}$ & $\begin{array}{c}\text { Affected } \\
\text { Skin Areas }\end{array}$ & $\begin{array}{c}\text { MCL } \\
\text { Diagnosed } \\
\text { Because of } \\
\text { Skin } \\
\text { Lesions } \\
\end{array}$ & $\begin{array}{c}\text { Relapse } \\
\text { of MCL in } \\
\text { Skin }\end{array}$ & $\begin{array}{l}\text { Primary } \\
\text { Therapy }\end{array}$ & $\begin{array}{c}\text { Survival } \\
(\mathrm{mo})\end{array}$ & $\begin{array}{l}\text { Dead/ } \\
\text { Alive }\end{array}$ & $\begin{array}{c}\text { Follow-up } \\
\text { (mo) }\end{array}$ \\
\hline 1 & Male & NK & NK & NK & Shoulder left & NK & & NK & NK & NK & \\
\hline 2 & Male & 85 & $1 \mathrm{e}$ & $\mathrm{M}$ & Thigh left & $\mathrm{N}$ & $\mathrm{X}$ & $\begin{array}{l}\text { Vincristin, } \\
\text { cyclophosphamide, } \\
\text { R-Benda }\end{array}$ & 6 & Dead & \\
\hline 3 & Male & 45 & 4 & M & NK & NK & & R-CHOP/R-DHAP & 42 & Dead & \\
\hline 4 & Male & 68 & $4 \mathrm{ae}$ & M & Both legs & $\mathrm{Y}$ & & R-CHOP & 62 & Dead & \\
\hline 5 & Male & NK & NK & NK & Back & $\mathrm{N}$ & $\mathrm{X}$ & STX & NK & NK & \\
\hline 6 & Male & 74 & $1 \mathrm{e}$ & $\mathrm{I}$ & Lower leg right & Y & & Surgery & & Alive & 5 \\
\hline 7 & Male & 76 & NK & NK & Skin NK & $\mathrm{N}$ & $\mathrm{X}$ & NK & NK & NK & \\
\hline 8 & Male & 82 & $4 a$ & $\mathrm{M}$ & $\begin{array}{c}\text { Lower leg } \\
\text { right }+ \text { several SC } \\
\text { lesions }\end{array}$ & $\mathrm{Y}$ & & Surgery & 26 & Dead & \\
\hline 9 & Male & 50 & 3 & $\begin{array}{l}\text { I at ID; } M \text { at } \\
\text { relapse }\end{array}$ & Scalp & $\mathrm{Y}$ & & $\mathrm{R}-\mathrm{CHOP}$ & 107 & Dead & \\
\hline 10 & Male & 84 & $4 e$ & I & Forearm & $\mathrm{Y}$ & & R-Benda & & Alive & 11 \\
\hline 11 & Male & 55 & 4 & M & Lower leg left & $\mathrm{N}$ & $\mathrm{X}$ & R-CHOP/R-DHAP & 133 & Dead & \\
\hline 12 & Female & 77 & 4 & M & Both lower legs & $\mathrm{N}$ & $\mathrm{X}$ & $\mathrm{R}-\mathrm{FC}$ & 85 & Dead & \\
\hline 13 & Male & 70 & 4 & M & Back & $\mathrm{Y}$ & & No therapy & & Alive & 9 \\
\hline 14 & Male & 69 & $4 \mathrm{~b}$ & I & Lower leg & $\mathrm{N}$ & $\mathrm{X}$ & R-Benda & & Alive & 60 \\
\hline
\end{tabular}

I indicates isolated; ID, initial diagnosis; M, multiple; N, no; NK, not known; R-Benda, rituximab-bendamustin; R-CHOP, rituximab, cyclophosphamide, doxorubicin, vincristine, prednisone; R-DHAP, rituximab, dexamethasone, cytarabine, cisplatin; R-FC, rituximab, fludarabine, cyclophosphamide; SC, subcutaneous; STX, stem cell transplantation; Y, yes. 
patients the leg lesions were the site of primary manifestation of the MCL before any other lymphoma manifestation was clinically evident. Other sites of skin manifestation were the trunk $(3 / 12,25 \%)$, the scalp $(1 / 12,8 \%)$, and the upper extremity $(1 / 12,8 \%)$. The clinical presentation of the skin manifestations varied; they were described as small nodules, erythematous patches/plaques or largely infiltrated areas (Figs. 1, 2). Most patients received chemotherapy as primary therapy $(8 / 12$ patients, Table 1$)$. For $7 / 11(63 \%)$ patients follow-up data were available (6 to $133 \mathrm{mo}$ ). In this subgroup of patients the median survival was 62 months.

\section{Histopathologic Features}

Table 2 summarizes the histopathologic, molecular, and immunophenotypic characteristics of MCL with skin involvement. The cytology was blastoid in 12/14 (86\%) cases and classical in 2/14 (17\%). All cases were positive for CD20, except for 1 , which showed skin involvement at relapse after prior anti-CD20 therapy. Nuclear staining for cyclin D1 was detected in every case $(14 / 14,100 \%)$. All evaluable cases reacted strongly positive for $\operatorname{Bcl} 2(11 / 11,100 \%)$. Expression of IgM and Mum-1 was observed in 10/12 (83\%) and 9/11 $(81 \%)$ cases, respectively. Expression of CD10 was found in
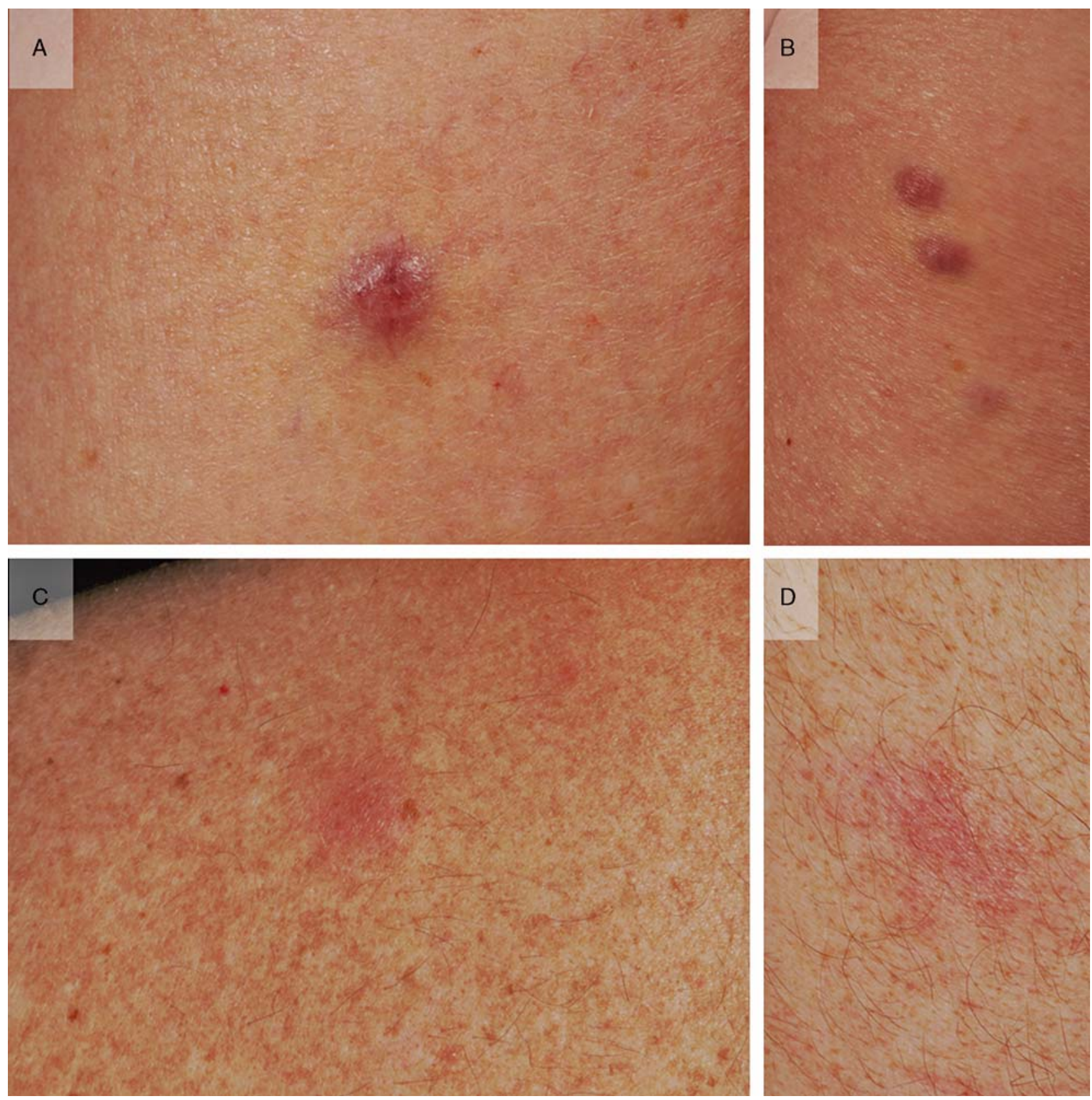

FIGURE 1. Clinical presentation of MCL in the skin can be polymorphous: Presenting as small nodules ( $A$ and $B)$ on the trunk and leg in 1 patient or slightly infiltrated patches on the chest and back ( $C$ and $D)$ in 1 of the patients with composite lymphoma. 

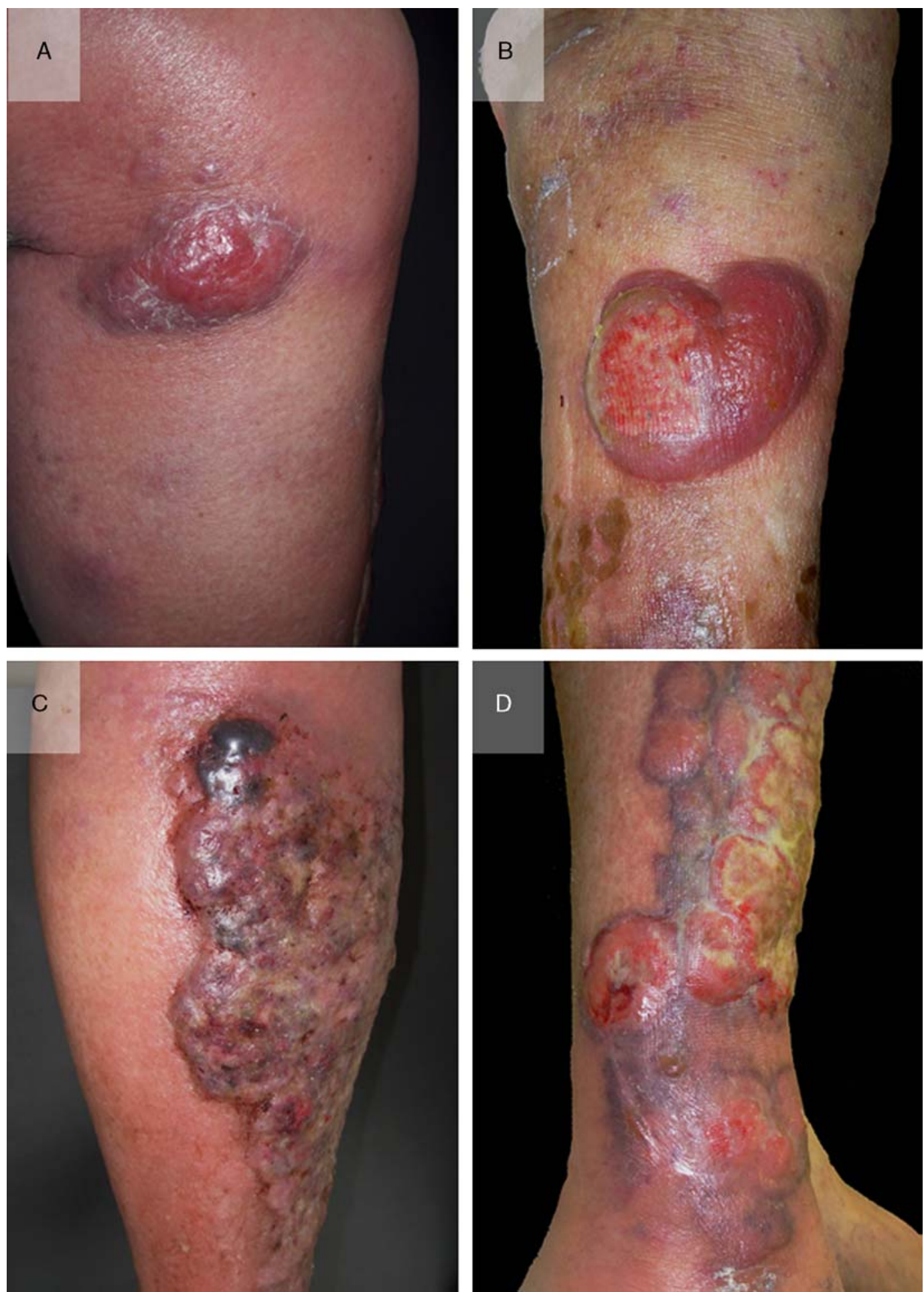

FIGURE 2. Clinically similar presentation of $\mathrm{MCL}(A$ and $C)$ and $\mathrm{pCDLBCL}(B$ and $\mathrm{D})$ on the leg with tumorous infiltration and heavily infiltrated areas with ulceration.

$3 / 13(23 \%)$ cases. BCL6 expression was not detected $(0 / 11$, $0 \%)$. P53 was expressed in 9/11 (81\%) cases. Sox11 was positive in $11 / 11(100 \%)$ MCL cases. Most lymphomas showed $\lambda$ light chain restriction $(7 / 11,64 \%)$, whereas $\kappa$ was less frequently positive $(2 / 11,18 \%)$. No plasmacytic differ- entiation of the MCL or strong expression of cytoplasmic light chains was observed. The proliferation rate was high (mean $60 \%$, median $80 \%$ ) and $>40 \%$ in all cases. Figure 3 exemplifies the immunophenotype of a patient with MCL in the skin with blastoid cytology. 
TABLE 2. Histopathologic Characteristics of MCL With Skin Involvement

\begin{tabular}{|c|c|c|c|c|c|c|c|c|c|c|c|c|c|c|c|c|}
\hline No. & Cytology & $\begin{array}{c}\text { Cyclin } \\
\text { D1 }\end{array}$ & CD20 & CD10 & CD5 & $\begin{array}{l}\text { CD23 } \\
\text { (Dendr) } \\
\end{array}$ & bcl2 & bcl6 & Mum-1 & $\begin{array}{l}\text { Ki67 } \\
(\%)\end{array}$ & IgM & $\kappa$ & $\lambda$ & p53 & Sox11 & $\begin{array}{c}\text { FISH } \\
\text { (Cyclin } \\
\text { D1-BA) }\end{array}$ \\
\hline $1^{*}$ & Small & + & + & - & + & $-(+)$ & + & - & $+1-$ & 50 & + & - & + & $-1+$ & + & + \\
\hline 3 & Blastoid & + & + & NM & + & - & NM & NM & NM & 80 & NM & NM & $\mathrm{NM}$ & NM & NM & NM \\
\hline 4 & Blastoid & + & + & - & $-/+$ & - & + & - & - & 42 & + & - & + & $+/-$ & $+/-$ & NM \\
\hline 5 & Blastoid & + & + & - & + & $-(-)$ & + & - & + & 70 & + & - & + & $+1-$ & $+1-$ & + \\
\hline 8 & Blastoid & $+1-$ & + & + & + & $-(-)$ & + & - & - & 60 & + & - & $-1+$ & $+/-$ & + & + \\
\hline 9 & Blastoid & + & + & - & + & $-(-)$ & + & - & $+/-$ & 90 & - & - & - & $+1-$ & $+/-$ & + \\
\hline 10 & Blastoid & + & + & - & $+/-$ & $-(-)$ & + & - & $+1-$ & 80 & + & - & + & $+1-$ & + & + \\
\hline 11 & Blastoid & + & $-\ddagger$ & + & + & $-(-)$ & + & - & + & 80 & + & - & $-/+$ & - & + & + \\
\hline 12 & Blastoid & + & + & - & NM & NM & $\mathrm{NM}$ & NM & NM & 50 & $\mathrm{NM}$ & NM & $\mathrm{NM}$ & NM & NM & + \\
\hline $13^{*}$ & Small & $-/+$ & + & - & + & $-(+)$ & $\S$ & $\S$ & $\S$ & $\S$ & $\S$ & $\S$ & $\S$ & $\S$ & $-1+$ & + \\
\hline
\end{tabular}

+ indicates $>75 \%$ of cells stained positive; eg. $+/->50 \% ;-/+>25 \% ;-<25 \%$.

*Patients with MCL + MZL.

$\dagger$ Evaluation for MCL only in the primary tumor.

$\Varangle$ Postchemotherapy with rituximab.

\$Main component was MZL, therefore no clear statement for immunohistochemistry in MCL is possible.

BA indicates break-apart; dendr, dendritic network; NM, no material.

The 2 cases of MCL with classical cytology that were identified in our study were detected within a skin lesion that resembled primary cutaneous marginal zone lymphoma (MZL). A distinction between the MCL and the MZL as separate entities is histopathologically feasible, as the MZL showed a $\lambda$ light chain-restricted plasma cell component that was cyclin D1 negative. Cyclin D1 expression was detectable in the centrocyte-like cells of the MCL, which were positive for $\kappa$ light chain (Fig. 4). It is worthy of mention that the MCL, but not the MZL, was Sox11 positive (Fig. 4). The intimate mixture of MCL and MZL in the lesion and the quality of the tissue (FFPE) prevented further molecular analysis. However, the restricted expression of Sox11 and cyclin D1 in the centrocyte-like cells and the different light chains in the plasma cells and centrocyte-like cells strongly argue against a plasma cell differentiation in the MCL and suggests 2 clonally unrelated diseases. Figure 4 illustrates the histopathology in one of the patients with a composite lymphoma. The MCL component in this case accounts for $50 \%$ of the infiltrate. In the second case the MCL component was limited to approximately $5 \%$ of infiltrate. The number of cyclin D1-positive cells correlated with the Sox11 expression level.

\section{Molecular Features}

All cases (12/12) with available material for fluorescence in situ hybridization analyses displayed a cyclin D1 break $(\mathrm{n}=5)$ and/or the presence of $\mathrm{t}(11 ; 14)(\mathrm{q} 13 ; \mathrm{q} 32)(\mathrm{n}=7)$.

\section{DISCUSSION}

This report represents the largest series of MCL infiltrating the skin published so far and describes the histomorphologic and clinical features of these cases. On the one hand, our data confirm findings of previously published smaller cohorts and case reports on MCL in the skin. On the other hand, our data have diagnostic implications for cuta- neous B-cell lymphomas and additionally provide new insight into the biology of MCL.

The frequency of approximately $1 \%$ of MCL showing skin involvement found in our single-center analysis closely matches the incidence described by the German Low-Grade Lymphoma Study group in a previous report. ${ }^{8}$ Previously published cohorts of MCL infiltrating the skin contain no more than 5 cases. ${ }^{6}$ Only recently, a review of the literature was published comprising a total of 22 cases. ${ }^{9}$ However, the diagnostic evaluation of the published cases was not performed according to current diagnostic criteria and frequently lacked staining for cyclin D1 or detection of $\mathrm{t}(11 ; 14)$. When we focused our literature review on the lymphomas clearly proven to be cyclin D1 positive, we identified 16 cases of MCL with skin involvement, most of which were described as single-case reports. ${ }^{10-13}$ Thus, despite the fact that the disease is leukemic in almost all cases $(87 \%$ of cases pretreatment) and frequently shows extranodal involvement, dermotropism is not a typical feature of $\mathrm{MCL}^{8,14}$

Most of the cases in our analysis as well as in the published literature showed systemic MCL at the time when skin manifestation occurred. However, of 16 published cases with MCL in the skin confirmed by cyclin D1 expression, 5 had involvement limited to the skin and lacked other manifestations (Table 3). ${ }^{6,9-13}$ Similarly, we identified 1 patient with an MCL confined to the skin at initial presentation. However, subsequent dissemination of the lymphoma cannot be excluded in our patient, as the follow-up period is short. Disseminated disease is present in most patients at the time of diagnosis. Nevertheless, the skin lesions can occur as the first manifestation of MCL, because in almost half of the patients in our cohort the skin was biopsied to establish the diagnosis. Our data strongly suggest that careful staging is mandated in any MCL within the skin to exclude disseminated disease. The 

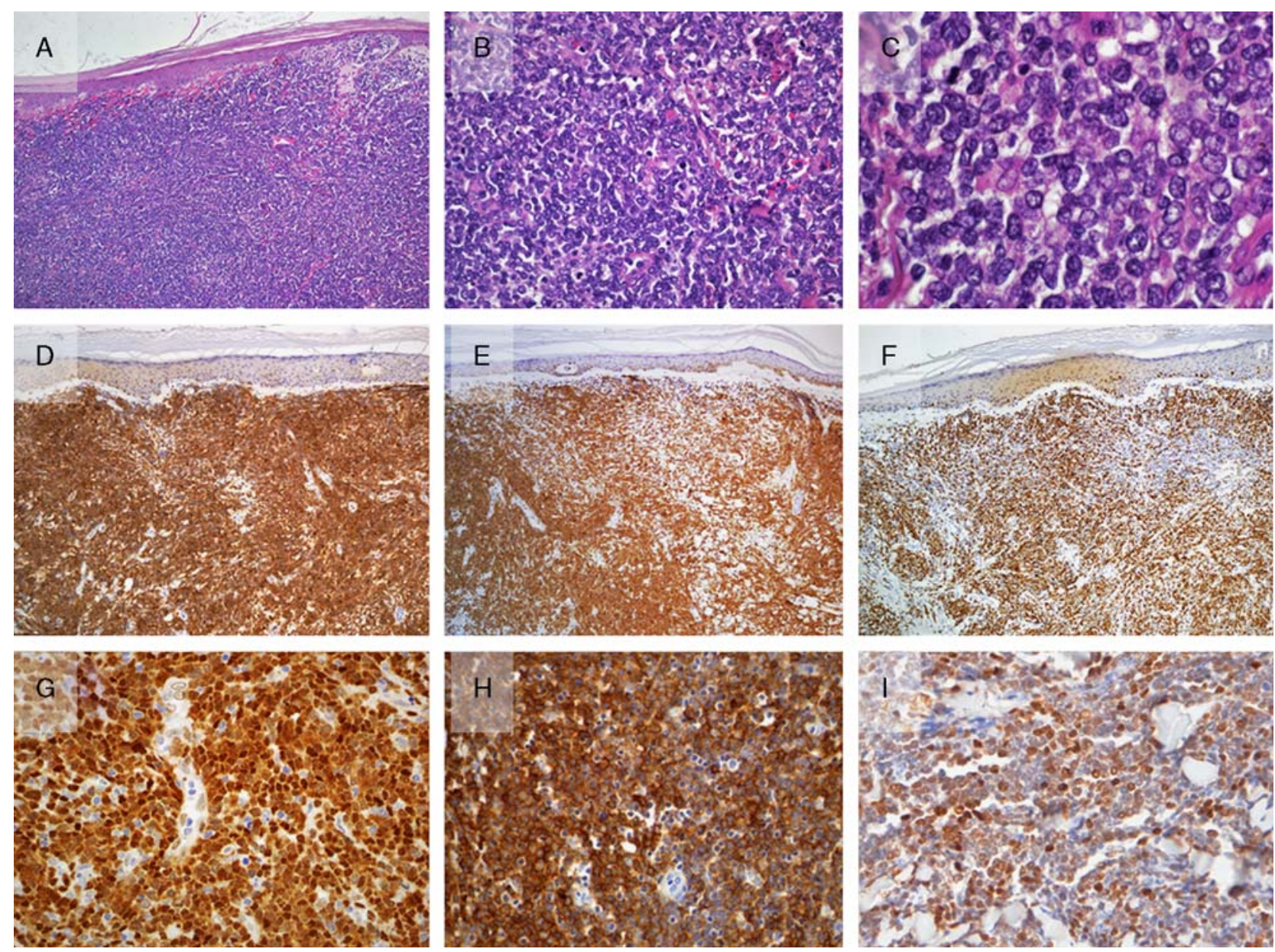

FIGURE 3. Histopathology of a blastoid MCL in the skin (patient no. 11; Table 3). Dense infiltrate in the upper dermis by large blastoid cells without alteration of the epidermis (A-C, hematoxylin and eosin in increasing magnifications). The malignant lymphoid cells express CD5 (D), Bcl2 (E), cyclin D1 (G), Mum-1 (H), and IgM (I). F, The proliferation rate as measured by Ki67 is high.

latter should be suspected in any patient warranting systemic treatment. 15,16

The majority of MCLs involving the skin in our cohort showed blastoid morphology, which is in line with the published literature (Table 3). Cases of blastoid MCL differ from classical MCL by their higher proliferation and poorer clinical outcome but also genetically by a higher level of genetic aberrations - for example, a high level of $\mathrm{p} 53$ inactivation. ${ }^{17,18}$ The dermotropism described in our study points to another biological feature of blastoid MCL that differs from classical MCL. The biological principles underlying the tissue manifestation of MCL are poorly understood so far. However, recent studies on a rare subtype of MCL presenting with little lymphadenopathy but high levels of leukemic spread and spleen involvement suggest that the expression of the transcription factor Sox11 is involved in the regulation of tissue manifestation - for example, by inducing blood vessel formation. ${ }^{19}$ Interestingly, all of the cutaneous MCLs in our cohort were Sox 11 positive. Sox 11 positivity is correlated with spread of the lymphoma in tissue. It is doubtful that Sox11 expression is the only factor influencing manifestation in the skin as this site of involvement is so rare. Presumably, there are other important features of these lymphomas leading to growth at this immune-privileged site. Another observation from our cohort points to a specific biological mechanism leading to skin manifestation in MCL. The only 2 cases with classical morphology in the skin were detected within a primary cutaneous MZL, the latter obviously being a clonally unrelated disease on the basis of the light chain expression. Unfortunately, the low level of MCL infiltration and the fact that only FFPE tissue was available prevented further molecular analysis in these cases. However, the skin involvement in these cases of classical MCL might be triggered by a disturbance of the cutaneous microenvironment. The physiological microenvironment of the skin seems to prevent MCL growth in the dermal compartment in the majority of cases. Our literature review did not identify any case report on the coexistence 


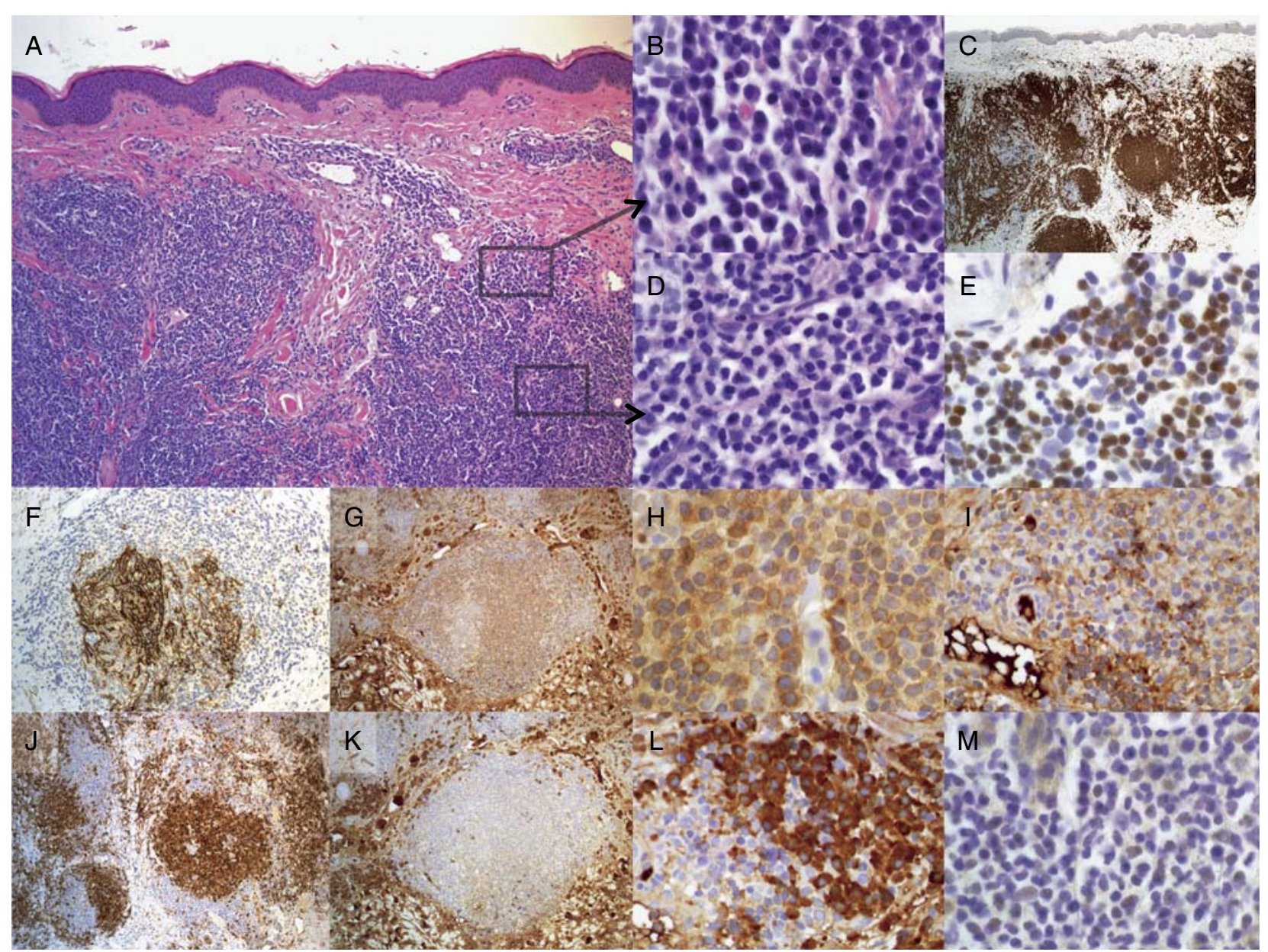

FIGURE 4. Histopathology of a cutaneous composite lymphoma consisting of a marginal zone LYMPHOMA and MCL. Alternatively marginal zone and mantle cell lymphoma. Dense nodular infiltrates in the upper dermis (A, H\&E). MCL component with small to medium-sized lymphoid cells $(B, H \& E)$ and $M Z L$ with plasmacytic differentiation (D, H\&E). Both components are positive for CD20 (C). MCL is positive for Sox11 (E) and cyclin D1 (J) and shows $\lambda$ light chain restriction (G and H). MZL shows $\kappa$ light chain restriction including a monotypic plasma cell component (K and L). No expression of $\kappa$ light chain in $M C L(M)$ and $\lambda$ light chain in MZL (I), respectively. CD23 highlights networks of follicular dendritic cells within the MCL component (F). H\&E indicates hematoxylin and eosin.

of MCL with other lymphomas or other neoplasms in the skin. Nevertheless, our findings suggest that in the diagnostic evaluation of indolent/small cell cutaneous B-cell lymphomas like MZL, cyclin D1 testing might be useful.

The most frequent primary cutaneous aggressive B-cell lymphoma, pcDLBCL-lt, is located predominantly on the leg. However, $58 \%$ of the MCL cases in our cohort were found on the leg as well, and the macroscopic picture was frequently indistinguishable from pcDLBCL-lt. Given the predominant blastoid morphology of MCL and the similarities in clinical presentation, we attempted to determine how likely it is that pcDLBCL-lt and skin manifestation of MCL might be confused if the immunophenotype is assessed. In fact, in addition to the morphology and clinical presentation, MCL and pcDLBCL-lt share many immunohistochemical features, such as the frequent expression of IgM, Bcl2, and Mum-1 as well as the absence of Bc16. Interestingly, CD10 expression was found in a similar percentage of blastoid MCL in the skin to that in pcDLBCL-lt (literature review in Table 4) ${ }^{20-26}$ Therefore, we conclude that skin involvement of MCL might erroneously be diagnosed as pcDLBCL-lt if no cyclin D1 staining is performed in a mature aggressive B-cell lymphoma presenting with skin lesions.

In summary, skin involvement is a rare presentation of MCL usually occurring as a secondary involvement by a systemic lymphoma. Skin tropism seems to be restricted to the more aggressive blastoid variant of MCL and consequently to be associated with an aggressive clinical course. Finally, skin involvement by MCL shares many clinical and histomorphologic features with pcDLBCL-lt: localization on the leg of elderly adults, blastoid cytology, and expression of Bcl2, Mum-1, and IgM. Thus cyclin D1 expression should be analyzed in any mature aggressive B-cell lymphoma in the skin. 
TABLE 3. Overview of Reported Case of Cyclin D1+MCL With Skin Involvement

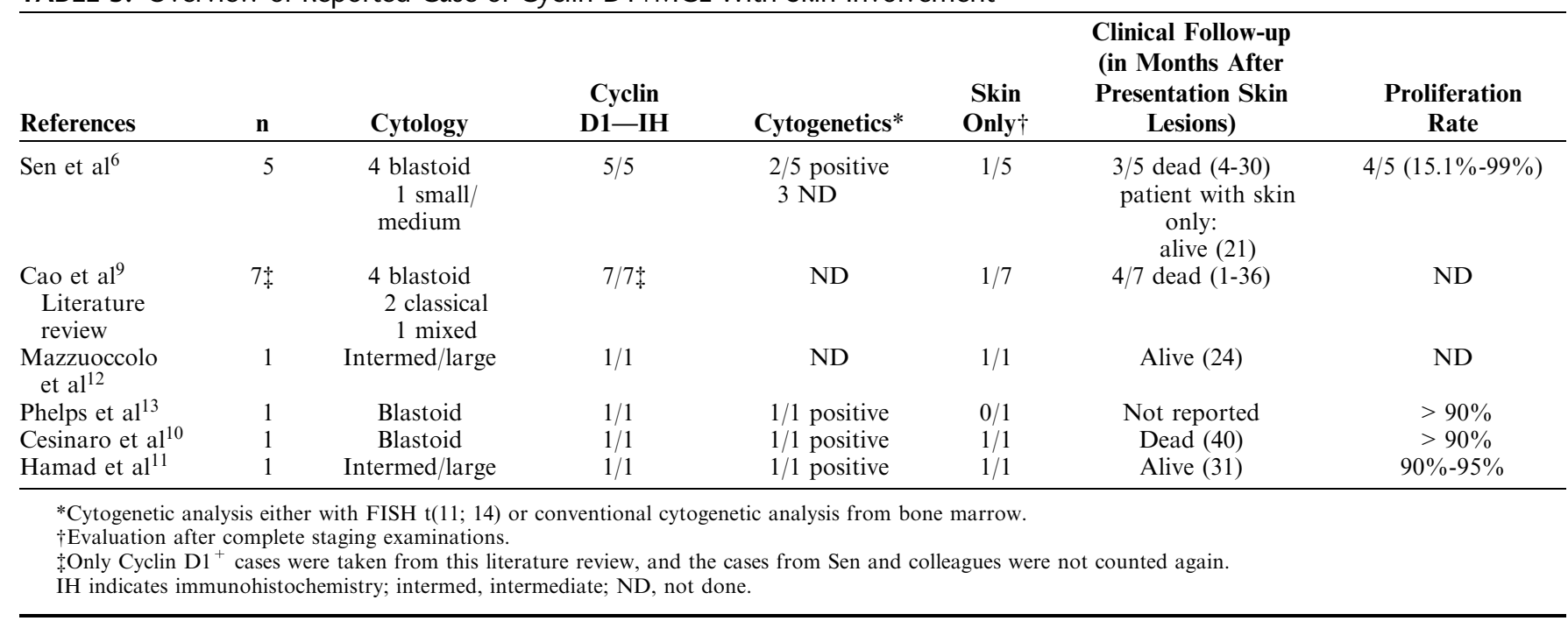

TABLE 4. Immunohistochemical Characterization of pcDLBCL-It $(n>10)$ in Comparison With MCL in Skin in Our Series

\begin{tabular}{|c|c|c|c|c|c|c|c|c|}
\hline Group & Diagnosis & $\mathbf{n}$ & $\begin{array}{c}\text { IgM } \\
\text { (n [\%]) }\end{array}$ & $\begin{array}{c}\text { Bcl6 } \\
\text { (n [\%]) }\end{array}$ & $\begin{array}{c}\text { Bcl2 } \\
(\mathrm{n}[\%])\end{array}$ & $\begin{array}{c}\text { CD10 } \\
\text { (n [\%]) }\end{array}$ & $\begin{array}{l}\text { Mum-1 } \\
\text { (n [\%]) }\end{array}$ & $\begin{array}{c}\kappa-\lambda \\
(\mathrm{n}[\%])\end{array}$ \\
\hline Demirkesen et $\mathrm{al}^{20}$ & pcDLBCL & 10 & $10 / 10(100)$ & $2 / 10(20)$ & $9 / 10(90)$ & $0 / 10(0)$ & $10 / 10(100)$ & ND \\
\hline Koens et $\mathrm{al}^{21}$ & pcDLBCL-lt & 40 & $40 / 40(100)$ & $18 / 40(45)$ & $36 / 40(90)$ & ND & $35 / 40(88)$ & $26 / 40(65)-13 / 40(33)$ \\
\hline Hallermann et $\mathrm{al}^{23}$ & pcDLBCL-lt & 21 & ND & $12 / 21(57)$ & $21 / 21(100)$ & ND & $19 / 21(90)$ & ND \\
\hline Kodama et $\mathrm{al}^{24}$ & pcDLBCL-lt & 40 & ND & $30 / 40(75)$ & $40 / 40(100)$ & $2 / 33(6)$ & $22 / 29(75)$ & ND \\
\hline Hoefnagel et $\mathrm{al}^{25}$ & pcDLBCL-lt & 19 & ND & $17 / 19(89)$ & $17 / 19(89)$ & $0 / 19(0)$ & ND & ND \\
\hline
\end{tabular}

BCL indicates B-cell lymphoma; ND, not done.

\section{ACKNOWLEDGMENTS}

The authors thank Charlotte Botz-von Drathen and Olivera Batic for their technical assistance. We also thank Kay Dege for editing the manuscript and Arne Voss for technical support.

\section{REFERENCES}

1. Swerdlow SH, Campo E, Harris N, et al. WHO Classification of Tumors of the Haematopoietic and Lymphoid Tissues. Lyon: IARC; 2008.

2. Tiemann M, Schrader C, Klapper W, et al. Histopathology, cell proliferation indices and clinical outcome in 304 patients with mantle cell lymphoma (MCL): a clinicopathological study from the European MCL Network. Br J Haematol. 2005;131:29-38.

3. Ganapathi KA, Pittaluga S, Odejide OO, et al. Early lymphoid lesions: conceptual, diagnostic and clinical challenges. Haematologica. 2014;99:1421-1432.

4. Argatoff LH, Connors JM, Klasa RJ, et al. Mantle cell lymphoma: a clinicopathologic study of 80 cases. Blood. 1997;89:2067-2078.

5. Dubus P, Young P, Beylot-Barry M, et al. Value of interphase FISH for the diagnosis of $\mathrm{t}(11: 14)(\mathrm{q} 13 ; \mathrm{q} 32)$ on skin lesions of mantle cell lymphoma. Am J Clin Pathol. 2002;118:832-841.

6. Sen F, Medeiros LJ, Lu D, et al. Mantle cell lymphoma involving skin: cutaneous lesions may be the first manifestation of disease and tumors often have blastoid cytologic features. Am J Surg Pathol. 2002;26:1312-1318.

7. Klapper W, Hoster E, Determann O, et al. Ki-67 as a prognostic marker in mantle cell lymphoma-consensus guidelines of the pathology panel of the European MCL Network. J Hematopathol. 2009;2:103-111.

8. Klapper W, Wacker HH. Follicular and mantle cell lymphoma. Extranodal involvement of primarily nodal indolent B-cell lymphomas. Pathologe. 2007;28:21-28.

9. Cao Q, Li Y, Lin H, et al. Mantle cell lymphoma of blastoid variant with skin lesion and rapid progression: a case report and literature review. Am J Dermatopathol. 2013;35:851-855.

10. Cesinaro AM, Bettelli S, Maccio L, et al. Primary cutaneous mantle cell lymphoma of the leg with blastoid morphology and aberrant immunophenotype: a diagnostic challenge. Am J Dermatopathol. 2014;36:e16-e18.

11. Hamad N, Armytage T, McIlroy K, et al. Primary cutaneous mantle-cell lymphoma: a case report and literature review. J Clin Oncol. 2014. [Epub ahead of print].

12. Mazzuoccolo LD, Castro Perez GA, Sorin I, et al. Primary cutaneous mantle cell lymphoma: a case report. Case Rep Dermatol Med. 2013;2013:394596.

13. Phelps A, Elaba Z, Murphy MJ. Blastoid mantle cell lymphoma with cutaneous involvement and aberrant immunophenotype. Am J Dermatopathol. 2014;36:526-527. 
14. Bottcher S, Ritgen M, Buske S, et al. Minimal residual disease detection in mantle cell lymphoma: methods and significance of four-color flow cytometry compared to consensus IGH-polymerase chain reaction at initial staging and for follow-up examinations. Haematologica. 2008;93:551-559.

15. Dreyling M, Geisler C, Hermine O, et al. Newly diagnosed and relapsed mantle cell lymphoma: ESMO Clinical Practice Guidelines for diagnosis, treatment and follow-updagger. Ann Oncol. 2014; 25(suppl 3):iii83-iii92.

16. Zelenetz AD, Gordon LI, Wierda WG, et al. Non-Hodgkin's lymphomas, version 42014J Ntl Compr Canc Netw. 2014;12:1282-1303.

17. Hoster E, Klapper W, Hermine O, et al. Confirmation of the mantle-cell lymphoma International Prognostic Index in randomized trials of the European Mantle-Cell Lymphoma Network. J Clin Oncol. 2014;32:1338-1346.

18. Salaverria I, Zettl A, Bea S, et al. Specific secondary genetic alterations in mantle cell lymphoma provide prognostic information independent of the gene expression-based proliferation signature. $J$ Clin Oncol. 2007;25:1216-1222.

19. Palomero J, Vegliante MC, Rodriguez ML, et al. SOX11 promotes tumor angiogenesis through transcriptional regulation of PDGFA in mantle cell lymphoma. Blood. 2014;124:2235-2247.

20. Demirkesen C, Tuzuner N, Esen T, et al. The expression of IgM is helpful in the differentiation of primary cutaneous diffuse large B cell lymphoma and follicle center lymphoma. Leuk Res. 2011;35: 1269-1272.

21. Koens L, Vermeer MH, Willemze R, et al. IgM expression on paraffin sections distinguishes primary cutaneous large B-cell lymphoma, leg type from primary cutaneous follicle center lymphoma. Am J Surg Pathol. 2010;34:1043-1048.

22. Grange F, Beylot-Barry M, Courville P, et al. Primary cutaneous diffuse large B-cell lymphoma, leg type: clinicopathologic features and prognostic analysis in 60 cases. Arch Dermatol. 2007;143: 1144-1150.

23. Hallermann C, Niermann C, Fischer RJ, et al. New prognostic relevant factors in primary cutaneous diffuse large B-cell lymphomas. J Am Acad Dermatol. 2007;56:588-597.

24. Kodama K, Massone C, Chott A, et al. Primary cutaneous large B-cell lymphomas: clinicopathologic features, classification, and prognostic factors in a large series of patients. Blood. 2005;106:2491-2497.

25. Hoefnagel JJ, Vermeer MH, Jansen PM, et al. Bcl-6 and CD10 expression in cutaneous B-cell lymphoma: further support for a follicle centre cell origin and differential diagnostic significance. $\mathrm{Br} J$ Dermatol. 2003;149:1183-1191.

26. Fernandez-Vazquez A, Rodriguez-Peralto JL, Martinez MA, et al. Primary cutaneous large B-cell lymphoma: the relation between morphology, clinical presentation, immunohistochemical markers, and survival. Am J Surg Pathol. 2001;25:307-315. 